Doi: $\underline{\mathrm{dx} . \text { doi.org/10.17921/2525-5320.2016.85-98 }}$

\title{
EDUCAÇÃO E ÉTICA NA ATUAÇÃO DO PROFESSOR DE EDUCAÇÃO INFANTIL: DESAFIOS PARA UMA PRÁTICA EMANCIPADORA
}

\author{
Sandra Regina Mantovani Leite* - UNESP
}

Palavras-chave: Formação de Professores. Educação. Ética. Infância.

\section{INTRODUÇÃO}

Este trabalho de pesquisa faz parte de um estudo maior intitulado: "Educação, Ética e Amizade: desafios na atuação do professor de Educação Infantil", que tem como objetivo principal analisar a relação entre educação, ética e amizade na atuação do professor da Infância, demonstrando sua importância quando esta é compromissada com uma educação emancipadora que possibilite às crianças se entenderem como sujeitos e produtores da sua história.

Para este trabalho objetivamos apresentar algumas considerações sobre a relação entre a Educação e a Dimensão Ética, como também analisar a importância da formação e atuação dos professores na Educação Infantil na busca de acolher, cuidar e educar as crianças pequenas, possibilitando a elas uma educação que priorize a sua construção como sujeitos históricos. Para tanto, elencamos a seguinte questão: Como a atuação do professor da infância pode possibilitar, por meio da Dimensão Ética, uma educação que favoreça a humanização e emancipação da criança?

$\mathrm{Na}$ Educação Infantil, os aspectos relacionados ao cuidado e ao acolhimento são prioritários. A educação e o fazer pedagógico junto às crianças pequenas não descartam as formas de cuidado/acolhimento, sendo elas necessárias para o pleno desenvolvimento das mesmas, portanto, defendemos com este trabalho a indissociabilidade entre o educar e o cuidar nesse primeiro nível da Educação Básica, entendendo o cuidado e o acolhimento numa perspectiva filosófica.

Neste estudo apresentaremos uma parte da pesquisa realizada em um Centro Municipal de Educação Infantil na cidade de Londrina, em que observamos crianças 
de 4 e 5 anos e suas relações com os professores e entre as próprias crianças no espaço da Instituição (salas, parques, refeitório, biblioteca).

A metodologia utilizada é o Estudo Etnográfico de Caso, com observações e entrevistas semiestruturadas realizadas com professores, coordenação e direção, além da conversa informal com as crianças durante as suas atividades, o que possibilitou uma triangulação de dados com a representação de professores e crianças sobre o que sentem e valorizam na interação que estabelecem.

Num primeiro momento apresentamos algumas considerações sobre a formação do professor de educação infantil, a relação entre a dimensão ética e a educação, como também a importância do cuidado e acolhimento neste momento da Infância. Num segundo momento, trazemos partes das entrevistas analisadas pela teoria apresentada.

\section{DESENVOLVIMENTO}

\section{A Educação e sua relação com a Dimensão Ética}

Temos como premissa uma concepção de homem como um ser histórico, em constante processo de mudança e em devir, sendo a sua ação uma prática intencionalizada, com objetivos e fins e, portanto, com uma consciência subjetiva que medeia sua intencionalização, sendo "essa consciência capaz de elaborar sentidos e de sensibilizar-se a valores" (SEVERINO, 2005, p.147). A ação pedagógica traz em seu bojo a intenção de possibilitar uma mudança, seja em qualquer grau, de um grupo ou até mesmo de um único indivíduo. Dessa forma, quando falamos em ação pedagógica estamos falando em ação humana, haja vista que não podemos correr o risco de pensarmos na Pedagogia e nas suas formas de ação apenas como meros receituários, como uma ciência empírica, reduzindo o fazer do professor a técnicas e instrumentos que potencializam o ensino e a aprendizagem.

Assim, ao analisarmos a relação da educação com a ética, somos conduzidos a um terreno especificamente humano, haja vista que é esse caráter não natural que nos move a pensarmos na importância da sua relação com a prática educativa, pois "o comportamento moral pertence somente ao homem na medida em que, sobre a sua própria natureza, cria esta segunda natureza, da qual faz parte a sua atividade moral" (VÁZQUEZ, 1982, p.14). 
Portanto, ao refletir sobre o campo educativo e sua relação com a dimensão ética, o que se percebe é que não existem costumes, modos de ser na natureza quando nos vemos como pertencentes ao reino animal, mas como homens, que fazem parte de uma humanidade, temos que cada cultura, por meio de um processo histórico e social inventa uma maneira de viver e se acostuma a isso. Acostumamonos e valorizamos qualificando de bom. Qualificamos de mal aquilo que não é costumeiro, que não faz parte do nosso modo de ser e de viver, sustentando assim o jeito de cada sociedade, com regras, normas e leis, aqui encontramos o comportamento moral (RIOS, 2000). A estas leis e regras podemos cumprir ou desobedecer, exercendo assim a liberdade humana, a possibilidade de escolhas, pois, se por moral temos o conjunto de prescrições, regras e normas que orientam a nossa sociedade, com a ética temos a reflexão sobre o ethos, que constitui a moralidade. Como homem faz-se necessário refletir sobre vida humana com o objetivo de torná-la melhor, pois agir eticamente conduz o homem a um aperfeiçoamento do conviver, numa ação reflexiva para valorizar o Bem Comum.

Chauí (1994, p.340) esclarece que: "a ação ética ancora-se, pois, na intencionalidade da ação, na relação da consciência para consigo mesma, na integridade do ser humano frente aos seus semelhantes".

\begin{abstract}
Viver sob parâmetros éticos requer a eleição de princípios do agir em consonância com os quais se possa pautar a trajetória de vida. Mas as escolhas não estão dadas na partida. É necessário - e recomendável - um exercício continuado para aprender a escolher, no plano de valores. Em última análise, tal atitude de escolha e de aprendizado das escolhas perdura no decorrer de toda a nossa vida (BOTO, 2001, p.122).
\end{abstract}

O sujeito moral é aquele capaz de decidir, de escolher, capaz de distinguir entre o bem e o mal, sendo que a inter-relação entre o tema ética e a matéria educativa está justamente entre a autonomia da vontade e a possível formação pedagógica que habilita o professor (BOTO, 2001).“Do ponto de vista ético, a ação humana precisa orientar-se por um conjunto de valores, qualificado de virtudes, as quais descrevem, possibilitam e realizam a finalidade humana" (RAMOS, 2011, p.29).

Ao buscar a íntima relação entre a ética e a educação podemos ressaltar que é necessário que a instituição escolar busque um educar para o viver bem, proporcionando vivências prazerosas e contextualizadas, que são também 
necessárias na aquisição dos conhecimentos básicos. Segundo Hermann (2008), a importância da reflexão, está em iluminar todo o processo educativo e argumentativo, auxiliar na formação humana por meio de uma reflexão crítica ligada às reais condições de vida. Considerar a importância da ética para o processo e para a prática educativa se apresenta como valorização do ser humano e de todas as suas manifestações:

\begin{abstract}
A abertura da ética para suas relações com a estética, como consequência do fracasso em considerar que a aprendizagem ética deveria apenas dialogar com o intelecto, sem se deixar influenciar pelas emoções, pelos sentimentos e pelas respostas sensíveis. Os princípios éticos, excessivamente abstratos, reverteram em perda de força persuasiva para as ações humanas, porque já não conseguem mais estabelecer vínculo com a situação concreta e muito menos servir como uma terapia da alma. (HERMANN, 2008, p.17).
\end{abstract}

O ser humano precisa ser visto como pessoa, como sujeito moral. "Pessoa é sujeito moral, investido de um valor absoluto [...] Esse valor é o que impede que uma pessoa possa ser tratada apenas como meio ou instrumento [...]" (MASSI; GIACÓIA Jr, 1998, p.356). Para tanto, uma educação ética pode auxiliar e se efetivar como uma arte de viver, nas palavras de Hermann (2008, p.26), sendo que as diferentes estratégias que permitem formar uma sensibilidade fortemente aguçada e atenta às emoções em relação à construção da moralidade "são contribuições da arte de viver que devem ser consideradas na educação, se quisermos educar pessoas com capacidade de decidir e conduzir suas vidas".

\title{
A formação do professor da educação infantil
}

Quando analisamos a formação do profissional da educação temos claro que essa preparação não acontece isolada, descontextualizada da forma como vivemos na sociedade e da maneira como entendemos a escola e a criança, no caso específico da Educação Infantil, muito se tem avançado teoricamente quando o assunto é infância e suas especificidades.

Com esse entendimento, a formação de professores, na maioria das vezes, por falta de interesse político e econômico, caminha em passos lentos, embora sejam muitas as experiências que motivam os formadores de professores e as universidades a buscarem novas formas de trabalho e propiciarem uma educação de qualidade aos futuros profissionais (CHAVES, 2007). 
Essas premissas vão ao encontro de defesas das políticas públicas voltadas para a infância na sociedade contemporânea, dentre elas, citamos: a Constituição Federal de 1988, que reconhece e defende a criança como um sujeito de direitos, principalmente o direito a uma educação de qualidade desde o nascimento; o Estatuto da Criança e do Adolescente - ECA, que dispõe sobre a proteção integral à criança e ao adolescente; a Lei de Diretrizes e Bases da Educação, que estabelece a Educação Infantil como primeira etapa da Educação Básica; e as Diretrizes Curriculares Nacionais para a Educação Infantil, as quais "destacam a necessidade de estruturar e organizar ações educativas com qualidade, articulada com a valorização do papel dos professores que atuam junto às crianças de 0 a 5 anos" (OLIVEIRA, 2010, p.1).

Esses avanços em termos de discurso exigem do profissional de Educação Infantil um novo perfil para organizar práticas intencionalmente dirigidas ao pleno desenvolvimento da inteligência e da personalidade da criança pequena. Com esse panorama legal, os professores são desafiados a planejar e a desenvolver propostas pedagógicas que, no cotidiano de Instituições de Educação Infantil, deem voz e vez às crianças e acolham a forma por meio da qual elas dão sentido ao mundo.

A educação, nesse sentido, precisa ser entendida, como ação e reflexão sobre a ação, como esforço histórico de autoconstituição da humanidade. A educação é a obra da práxis humana, é por isso que somente pela educação é que o homem se torna homem. E é na instituição escolar que o professor consciente do seu papel pode atuar buscando a humanização da sociedade, uma "tarefa mediadora do professor, entre a experiência do aluno e uma atividade crítica e cultural mais ampla" (GUZZO, 2011, p.47).

Daí a importância de um trabalho comprometido e contextualizado, com formadores de professores que atuem valorizando a pesquisa como articuladora na resolução de problemas profissionais e na construção de uma autonomia profissional, individual e coletiva, que desenvolva uma fundamentação teórica sólida da ação docente no desenvolvimento humano. "[...] ganha força a formação ética e política do professor no sentido de construir um novo projeto educacional, tendo como fundamento a forma de ação reflexiva" (GUZZO, 2011, p.46).

O professor é um trabalhador intelectual e precisa utilizar da prática educativa buscando a transformação social. A atividade intelectual e "intencional do educador que antevê o processo educativo de modo sintético, é, portanto, o elemento 
mediador que viabiliza essa transformação" (OLIVEIRA, 1985, p.100). Assim sendo, o professor com sua atividade mediadora intervém na prática educativa no sentido de instrumentalizar o indivíduo para sua atuação no meio social. Essa instrumentalização é possibilitada ao ser humano por meio do saber escolar, que é a ferramenta cultural necessária para intervir no mundo transformando-o, a dimensão epistemológica que contempla a razão e o conhecimento, a aquisição e a construção do sujeito como ser histórico e social é imprescindível para que este sujeito se entenda como pessoa.

Portanto, esta pesquisa não pretende retirar a importância e o valor da construção do sujeito por meio da aquisição do conhecimento elaborado pela humanidade. Objetiva sim, ressaltar que a atuação dos professores precisa priorizar a democracia no espaço educativo e nas relações humanas. E é nesse sentido, ao falarmos da formação de professores para Educação Infantil, que se entende a importância de olhar para o outro como ser em desenvolvimento, que necessita de acolhimento e cuidados.

Nesse sentido, o professor pesquisador precisa estar consciente da sua atuação para enfrentar os desafios da sociedade e da escola contemporânea, deixando de ser um mero técnico científico, haja vista que formação é muito mais que domínio de conhecimento e aprendizagem de técnicas. Formação é exercício permanente de presença ativa no mundo, pensada a partir da perspectiva do compromisso ético, que utiliza do conhecimento, das técnicas, sem, contudo privilegiá-las. Sendo assim, a concepção do educador que se defende neste estudo é de um trabalhador intelectual que faz a sua parte na realização histórica, na humanização e emancipação da vida humana.

A emergência de uma nova escola, para que se possa compreender a crise da educação para uma nova atuação político-pedagógica transformadora, envolve a formação do professor, no sentido de construir-se a partir da consciência política e ética de sua práxis. A clareza e o respeito da natureza ética e política da educação poderá possibilitar ao professor auxílio a si e aos seus alunos, na medida em que o fará compreender que esses componentes fazem parte de maneira indissociável de sua formação. A escola, inserida em um ambiente social, terá a possibilidade de receber melhor análise crítica se os fundamentos das ações docentes se voltarem para a tarefa de construção da cidadania para todos: alunos e professores. (GUZZO, 2011, p. 44).

Faz-se necessário valorizar e lutar para que o profissional da educação tenha realmente uma formação inicial e permanente que contribua efetivamente para que 
sua prática seja significativa. A formação dos profissionais que atuam na educação infantil precisa proporcionar às crianças o contato com as experiências vivenciadas pelos adultos integrando as suas vivências, permitindo que a criança atue como sujeito social, histórico e cultural.

Deste modo, os professores necessitam refletir constantemente sobre sua prática, tendo para tanto uma fundamentação crítica coerente criando estratégias e atuando de forma comprometida, desvalorizando o uso de receituários e/ou manuais. O professor como agente de mudanças e promotor do saber precisa utilizar de sua atividade docente com a função de afetar, de sensibilizar os envolvidos nesta experiência que estejam dispostos a dar-lhe significado. significado se efetiva à medida que as pessoas aprendem e apreendem envolvidas numa experiência em que são afetadas por ela, seja pela palavra, seja pela linguagem, por um gesto ou simplesmente por estarem dispostas a buscar a compreensão acerca de si ou do mundo.

\section{Educar, cuidar e acolher: ações educativas em busca da humanidade do outro}

Em estudos apoiados na Filosofia da Educação, é possível perceber outros entendimentos com relação ao conceito de cuidado e que parecem ser pertinentes ao desenvolvermos esta reflexão sobre a Educação Infantil: o cuidado não se relaciona apenas e exclusivamente à necessidade de higiene ou cuidados com o corpo.

O cuidado implica em cuidar do outro em toda sua dimensão humana. Segundo Macêdo e Dias (2006) o termo cuidado é derivado do latim cogitatus e apresenta uma dupla função de entendimento. No primeiro sentido, refere-se à atividade de pensamento, com a função de adjetivo e particípio do verbo cuidar, implicando em pensado, calculado, suposto, meditado. O segundo entendimento da palavra referese ao campo das emoções, aparece com a função de substantivo masculino, significando desvelo, solicitude, diligência, vigilância, precaução.

Dessa forma, pode-se afirmar que a prática do cuidado também apresenta duplo sentido, um deles no campo da ação do pensamento, reflexão, e outro no campo da aplicação do espírito, apresentando-se em atitudes de relacionamento para com o outro. Nesse sentido e principalmente tendo como foco a criança na Educação Infantil, pode-se afirmar que cuidar abrange aspectos cognitivos e afetivos. 
O cuidado se relaciona com a dimensão ética na prática educativa, o ser humano precisa ser visto como pessoa, valorizado como pessoa e a atuação do professor precisa proporcionar aos que estão na condição de aprendentes as possibilidades de se construírem como seres humanos. Segundo Folque (2014, p. 75) "aprender significa uma mudança de participação em práticas sociais, que passa de uma participação periférica para uma participação plena na comunidade da sala do jardim-de-infância", sendo que para tanto, uma Educação Ética, que privilegia o cuidado e o acolhimento pode auxiliar e se efetivar como uma arte de viver, valorizando o espaço educativo como comunidade de aprendentes, em que a aprendizagem é um "projecto de acção partilhado".

É na relação social, na relação com os outros que a ética se desenvolve, não se forma o ser ético apenas pelo conhecimento. A ética fala ao espírito e a alma, só pode ser reconhecida quando praticada, então para se tornar bom, é preciso praticar atos bons.

[...] o carácter vinculante do cuidado, como modo de ser e estar uns com os outros num mundo freneticamente impulsionado pelo desenvolvimento técnico-científico, politicamente gerido, e regido por leis, que um só imperativo, único e primordial, deve ter vigência: a responsabilidade como princípio e os corolários da sua aplicação (BORGES-DUARTE, 2010, p.126).

Nessa perspectiva, as reflexões sobre a educação de crianças implicam discussões sobre o cuidado, como forma de estar com o outro e valorizá-lo como pessoa, como principal responsabilidade e, consequentemente, o acolhimento em decorrência. Faz-se necessário valorizarmos o ser e estar juntos, os momentos em que estamos com as crianças. Criar outra forma social de cuidado. É preciso cultivar aquilo de que se cuida. Fazer frutificar e transformar as relações que se estabelecem no interior das Instituições de Educação Infantil, de tal modo que na educação das crianças exista a exigência de formá-las para tomar cuidado de si própria e dos outros, e não só deixá-las receber cuidados dispensados por um poder, qualquer que ele seja, e em nome de alguns saberes, quaisquer que eles sejam (BORGES-DUARTE, 2010).

O processo de cuidado e educação das crianças pequenas se torna mais efetivo e, por conseguinte, prazeroso quando há um envolvimento real, uma sintonia entre quem cuida e quem é cuidado, por meio da qual a professora é capaz de ler as múltiplas expressões das crianças, suas formas diferenciadas de comunicação e ação e intervém no sentido de acolher e envolver a criança no espaço educativo, contribuindo para o 
desenvolvimento integral da mesma, o que pressupõe a indissociabilidade de ambas as ações (MACÊDO; DIAS, 2006, p.5).

Nessa perspectiva, faz-se necessário afirmar que o professor por meio da sua atuação com práticas que valorizam o educar e o cuidar potencializa habilidades, conhecimentos e experiências que contribuem para o desenvolvimento pleno da criança. Esse trabalho que tem como foco o outro e o relacionamento entre os pares contribui para a educação democrática, para uma prática pedagógica que priorize a emancipação da criança, sujeito de direitos e entendida como cidadã. Práticas que favoreçam a participação de todos nas atividades, em que todos sejam ouvidos com professores que saibam ouvir, que prestem atenção no que as crianças querem dizer e que principalmente respeitem a forma de expressar das produções infantis. Uma postura docente que valorize a dimensão ética e estética em defesa da expressão de sentimentos e pensamentos em defesa do direito à diversidade e à pluralidade.

Nesse sentido, percebe-se a importância que as ações de cuidado e de acolhimento do outro, como pessoa, favorecem no desenvolvimento da criança, com atitudes racionais, pois o professor planeja e organiza o trabalho pedagógico no sentido de priorizar o desenvolvimento integral da criança, como também são interativas, pois demanda o desvelo, a criação de vínculos, o acolhimento do outro apesar das diferenças, a construção de conhecimentos culturais e atitudes sociais.

\begin{abstract}
a cisão entre as ações de educar e cuidar se configura como uma atitude incoerente e inconsequente que tem imprimido a educação infantil marcas de fragmentação e inconsistência manifestas por diferentes concepções e ideologias. Ademais, acolher a criança do ponto de vista integral, implica em atender suas individualidades, compreender suas manifestações emocionais, agir sobre elas, acatá-las como linguagem própria das crianças pequenas, dar e receber afeto, proporcionar o desenvolvimento da autonomia, por fim, contribuir para a constituição do eu da criança. (MACÊDO; DIAS, 2006, p.5)
\end{abstract}

Assim, torna-se essencial definir propostas pedagógicas concretizadas por meio de práticas educativas que favoreçam o diálogo, a participação e a negociação. Sobretudo, práticas pautadas em valores que proporcionem às crianças direito de expressar seus pontos de vista, de ter voz e vez, com possibilidades de compartilhar ideias, experimentar o mundo, transformando a Instituição de Educação Infantil um espaço de comunicação, de apropriação de conhecimentos e, consequentemente, de humanização. 


\title{
Para não concluir: o que a realidade nos inquieta? ${ }^{1}$
}

Percebemos que o espaço das Instituições de Educação Infantil carece de muitos recursos. Recursos que vão desde a falta de equipamentos no espaço externo, como parques e área coberta para o desenvolvimento de atividades ao ar livre, como também recursos humanos que possam disponibilizar um contato mais próximo com as crianças. Por meio das observações que realizamos no Centro de Municipal de Educação Infantil podemos presenciar momentos em que as crianças ficam sem ter o que fazer por muito tempo: Estão no parque, no pátio, sem direcionamento, sem brinquedos, com alguns potes de sorvetes que servem apenas para mexer nas pedrinhas que escondem a terra que fica no parque infantil. $O$ parque é sucateado com poucos brinquedos de ferro, que por norma da $\mathrm{ABNT}^{2}$, não devem ser mais utilizados com a criança na primeira infância.

O entendimento dos professores com relação à criança, embora com mudanças no discurso teórico e na legislação/políticas públicas, ainda permanece como anteriormente para muitos da sociedade, como também entre pessoas que atuam diretamente com as crianças. A fala de duas professoras entrevistadas demonstra isso:

\begin{abstract}
A nossa função social ainda hoje é assistencialista. Se vê mais como assistencialismo, é um local por parte da comunidade, por parte do poder público, da Secretaria da Educação não. Do entendimento da nossa gerência, da nossa Secretária da Educação, a Educação Infantil é uma fase da educação mesmo, a gente até tem algum apoio. $O$ que barra 0 entendimento da Educação Infantil como base da Educação seria mais o poder judiciário e a comunidade.(aux 1$)^{3}$
\end{abstract}

entende-se sim que é um direito constitucional, que é um direito à educação, mas também tá dizendo lá que a educação tem que ser de qualidade, muitas pessoas tem o entendimento que a educação não é da criança. É do pai que precisa trabalhar. Então eles tem esse pensamento assistencial. A criança precisa da escola, porque o pai precisa trabalhar. Ela não precisa da escola, porque ela precisa se comunicar melhor, porque ela precisa aprender, porque ela precisa se socializar com outras crianças, que ela precisa da convivência do outro, precisa de toda essa parte que a El já proporciona. Então o entendimento da função do CEMEI ou da El hoje

\footnotetext{
1 Trazemos para reflexão uma parte da pesquisa realizada em um Centro Municipal de Educação Infantil na cidade de Londrina, em que observamos crianças de 4 e 5 anos e suas relações com os professores e entre as próprias crianças no espaço da Instituição.

${ }^{2}$ A norma da ABNT (NBR 14350) prevê, entre outras exigências, que os brinquedos não podem apresentar trincas, deformações ou danos permanentes e que nenhuma conexão pode estar frouxa. Projeto de Lei sobre esta questão está em tramitação na Câmara dos Deputados

3 Utilizaremos fragmentos das entrevistas realizadas com os professores, nomeando os mesmos com as siglas Aux 1, Aux 2, Prof 1 e Prof 2. Apresentamos as falas em itálico, transcrevendo originalmente.
} 
ainda está confuso.(aux 2)

As crianças precisam ser vistas e valorizadas como sujeito de direitos, pessoas ativas, participantes, protagonistas, como ser histórico e social que se apropria da cultura existente reproduzindo-a e modificando-a. Por isso, "não cabe à educação "fazer" pessoas, mas despertá-las para sua autonomia mediante os recursos da cultura. Educar-se é aprender-se e se constituir cada vez mais como sujeito." (SEVERINO, 2001, p.80) Assim o professor mediador nesse processo tem um papel importantíssimo para que o desenvolvimento e a aprendizagem da criança aconteça de forma plena e integral.

Uma das entrevistadas assinala a importância de todo o trabalho realizado:

ajudar no desenvolvimento da criança, porque as crianças ficam muito tempo com a gente, então o conhecer o mundo pra elas vai ser aqui através do nosso trabalho, através das experiências que nós vamos proporcionar, porque não é como antes, né, que as crianças tinham outras interações, tinha a família, tinha a rua, outras pessoas que cuidavam delas e tinham a oportunidade de passear e brincar, interagir, agora é tudo feito por nós, eles passam o dia aqui com a gente, então tudo o que eles conhecem é por nós em todos os sentidos, então a nossa função aqui é proporcionar o máximo de experiências pra eles se apropriarem do mundo que nos cerca, do mundo que a gente vive. (prof. 1)

A instituição de educação infantil precisa ser um espaço que potencializa a mediação e a realização da criança em sua plenitude. Um educando que se descobre como ser humano, com sua dignidade de ser pessoal, consciente e livre. $E$ o professor como principal agente desse processo também precisa utilizar de seu arcabouço teórico para potencializar as atividades que são realizadas no espaço educativo. As práticas pedagógicas que se relacionam com o educar, o cuidar e o acolher precisam iniciar com reflexões sobre a importância do que será realizado com a turma, para que as atividades que serão realizadas não sejam superficiais e sem objetivos pedagógicos consistentes e possibilitadores do desenvolvimento da criança. A fala de uma das professoras expressa essa preocupação:

a partir do momento de que ele não reflete sobre o seu trabalho, pensando
no seu trabalho, organizando. Ele se coloca como mero cuidador. A partir
do momento de que você pega planejamentos repetitivos, não no sentido de
que aquela criança precisa repetir alguns momentos, repetitivo mesmo. No
sentido de que não quero pesquisar então vou copiar e colar alguma coisa
que já fiz. (Aux 2)

Os professores precisam refletir constantemente sobre o que e como realizam, não podem atuar apenas para cumprir rotinas rígidas para a utilização dos espaços 
e das obrigatoriedades como as necessidades de higiene e alimentação. Todo o processo que acontece em um Centro de Educação Infantil é pedagógico, sendo que todas as relações que acontecem entre os envolvidos no processo educativo precisam propiciar o desenvolvimento pleno da criança em busca da emancipação e da autonomia.

Por meio desta pesquisa, que foi realizada no segundo semestre de 2015, podemos afirmar que a instituição escolar, especificamente a Instituição de Educação Infantil, pode e precisa buscar a integração entre as duas dimensões (epistemológica/conhecimento e ética/amizade) possibilitando uma educação emancipadora, que assuma sua função social como espaço de produção do novo, do resistente ao que já está instituído, de valorização da pessoa e das emoções.

Nesse sentido, acreditamos que a especificidade da docência do professor de educação infantil está em assegurar por meio da sua atuação a integração da educação e do cuidado em todos os momentos. A criança tem necessidade e direito de ser cuidada e acolhida como pessoa. E isto implica em atender suas individualidades, compreender suas manifestações emocionais, agir sobre elas, acatá-las como linguagem própria das crianças pequenas, dar e receber afeto, proporcionar o desenvolvimento da autonomia, por fim, contribuir para a constituição do eu da criança. (MACÊDO; DIAS, 2006).

A dimensão Ética inserida na prática do educador poderá aprofundar a reflexão sobre o que é realmente importante para o desenvolvimento da criança e de sua infância. O próprio Projeto Político Pedagógico que poderia auxiliar nesta reflexão constante não é visto como documento clarificador das ações pedagógicas na Instituição. As modificações ficam muito mais relacionadas com a questão burocrática do trabalho do diretor e auxiliar de supervisão que está no Centro de educação infantil.

\section{CONCLUSÃO}

Assim, acreditamos que para proporcionar o desenvolvimento da criança o professor deverá refletir sobre os acontecimentos de sua prática, permitindo que ela conheça diferentes vivências, que tenha acesso às diferentes culturas e modos de vida; estimulando o entrelaçamento de suas vivências aos novos conhecimentos, favorecendo o pensamento e a reflexão sobre essas diferenças para que tenha 
condições de se apropriar da cultura existente se apropriando e modificando-a, aceitando o diferente e ao mesmo tempo ampliando seus conhecimentos.

Diante do exposto avalia-se a importância desta discussão para a prática pedagógica na educação infantil e para a formação de professores, especialmente, porque se compreende que o trabalho na instituição escolar que valorize e trabalhe com a dimensão ética e atue de forma indissociável com o educar, cuidar e o acolher possibilitando aos envolvidos no processo educativo, uma educação humana e emancipadora que contemple o outro, em que professor e criança sejam afetados pela reflexão de seus limites, de suas possibilidades, de uma interação de amizade e respeito favorecendo a emancipação.

\section{REFERÊNCIAS}

BORGES-DUARTE, I. A fecundidade ontológica da noção de cuidado de Heidegger a Maria de Lourdes Pintasilgo. In: Ex æquo, $n .^{\circ}$ 21, Universidade de Évora, 2010, p. 115-131.

BOTO, C. Ética e educação clássica: virtude e felicidade no justo meio. Educ. Soc., v.22, n.76, 2001.

CHAVES, M. Práticas educativas e formação em serviço: reflexões e desafios que se apresentam aos profissionais da infância. In: RODRIGUES, E.; ROSIN, S.M. (Org.). Infância e práticas educativas. Maringá: Eduem, 2007. p.175-186.

CHAUÍ, M. Convite à filosofia. São Paulo: Ática, 1994.

FOLQUE, M.A.F. O aprender a aprender no pré-escolar: o modelo pedagógico do movimento da escola moderna. Lisboa: Fundação Calouste Gulbenkian, 2014.

HERMANN, N. Ética: a aprendizagem da arte viver. Educ. Soc., v.29, n.102, p.15-32, 2008.

OLIVEIRA, Z.R. O currículo na educação infantil: o que propõem as novas diretrizes nacionais? SEMINÁRIO NACIONAL: CURRÍCULO EM MOVIMENTO PERSPECTIVAS ATUAIS. 2010. Belo Horizonte, 2010. Anais... Belo Horizonte, 2010.

OLIVEIRA, B. A prática social global como ponto de partida e de chegada da prática educativa. In: OLIVEIRA, B; DUARTE, N. Socialização do saber escolar. São Paulo: Cortez, 1985. p.91-104.

MACÊDO, L.C.; DIAS, A.A. O cuidado e a educação enquanto práticas indissociáveis na educação infantil. In: REUNIÃO ANUAL DA ANPED, 29. 2006, Caxambu, MG. Educação, Cultura e Conhecimento na Contemporaneidade: Desafios e Compromissos, 2006. 
MASSI, C.D.B.; GIACÓIA JUNIOR, O. Ética e educação. In: SERBINO, R.V. et. al. Formação de professores. São Paulo: Unesp, 1998.

RAMOS, C.A. Ética e política em Aristóteles. In: CANDIOTTO, C. Ética: abordagens e perspectivas. Curitiba: Champagnat, 2011. p.29-49.

RIOS, T.A. Ética e competência. São Paulo: Cortez, 2000.

SEVERINO, A.J. Educação e ética no processo de construção da cidadania. In: GOERGEN, P.; LOMBARDI, C. (Org.). Ética e educação: reflexões filosóficas e históricas. Campinas: Autores Associados, 2005. p.137-154.

SEVERINO, A.J. Educação, sujeito e história. São Paulo: Olho d'Água, 2001.

VÁZQUEZ, A.S. Ética. Rio de Janeiro: Civilização Brasileira, 1982. 